\title{
Association Between Type 2 Diabetes and Classification of Periodontal Disease Severity in Japanese Men and Women: A Cross-Sectional Study
}

\author{
Nanae Dewake ( $\square$ nanae.dewake@mdu.ac.jp ) \\ Matsumoto Dental University \\ Yukiko Iwasaki \\ Matsumoto Dental University Hospital \\ Akira Taguchi \\ Matsumoto Dental University \\ Nobuyuki Udagawa \\ Matsumoto Dental University \\ Nobuo Yoshinari \\ Matsumoto Dental University
}

\section{Research Article}

Keywords: Type 2 diabetes, Periodontal disease severity, Alveolar bone loss rate, High-sensitivity Creactive protein

Posted Date: November 19th, 2021

DOI: https://doi.org/10.21203/rs.3.rs-1090945/v1

License: (c) (i) This work is licensed under a Creative Commons Attribution 4.0 International License.

Read Full License 
4 Running title: Association between Diabetes and Periodontal Condition

5 The proposed type of manuscript: original article

6 Names of authors: Nanae Dewake ${ }^{1}$, Yukiko Iwasaki ${ }^{2}$, Akira Taguchi ${ }^{3,4}$, Nobuyuki Udagawa ${ }^{3,5}$ and Nobuo

7 Yoshinari ${ }^{1,3}$

8 Authors' affiliations

$9 \quad{ }^{1}$ Department of Operative Dentistry, Endodontology and Periodontology, School of Dentistry, Matsumoto Dental

10 University, Shiojiri, Japan

$11 \quad{ }^{2}$ Department of Oral Sciences, Matsumoto Dental University Hospital, Shiojiri, Japan

$12{ }^{3}$ Department Oral Health Promotion, Graduate School of Oral Medicine, Matsumoto Dental University, Shiojiri,

13 Japan

$14{ }^{4}$ Department of Oral and Maxillofacial Radiology, School of Dentistry, Matsumoto Dental University, Shiojiri,

15 Japan

$16{ }^{5}$ Department of Biochemistry, School of Dentistry, Matsumoto Dental University, Shiojiri, Japan.

17 Corresponding author:

18 Name: Nanae Dewake

19 Current address: 1780 Gobara Hirooka Shiojiri, Nagano, 399-0781 Japan 
Email: nanae.dewake@mdu.ac.jp

Keywords

Type 2 diabetes, Periodontal disease severity, Alveolar bone loss rate, High-sensitivity C-reactive protein

24

Abstract

Background: To evaluate the association between type 2 diabetes and periodontal disease severity using the rate

of alveolar bone loss (ABL) and high-sensitivity C-reactive protein (hs-CRP) value as indices.

Methods: In this cross-sectional study of 372 subjects (mean age \pm SD, $53.2 \pm 11.8$ years) from a Japanese hospital,

we measured $\mathrm{ABL}$ and number of teeth on either panoramic radiographs or intraoral dental radiographs of all teeth.

A trial classification of periodontal disease was defined as follows: I ( $\mathrm{ABL}<25 \%$, clinically mild); II ( $\mathrm{ABL} \geq$

$\geq 440 \mathrm{ng} / \mathrm{ml},<1,020 \mathrm{ng} / \mathrm{ml}$, moderate inflammation); and C (hs-CRP $\geq 1,020 \mathrm{ng} / \mathrm{ml}$, severe inflammation).

Periodontal disease severity was classified into nine groups by combining ABL and hs-CRP.

34 Results: Forty-eight subjects had type 2 diabetes; 324 did not. Univariate analysis showed that type 2 diabetes

with high severity of periodontal disease. In receiver operating characteristic (ROC) curve analysis predicting the 
using the combination of ABL and hs-CRP.

The association between systemic health and oral health is bidirectional; systemic illnesses, especially

metabolic disorders, affect oral health, and it appears that oral health may affect systemic health [1]. The presence

of periodontal disease often strongly correlates with type 2 diabetes. Periodontal disease is a local chronic

inflammatory disease, initiated by the accumulation of a pathogenic dental plaque biofilm above and below the gum margin, within which microbial dysbiosis leads to a chronic non-resolving and destructive inflammatory response $[2,3]$. There is a strong evidence that people with periodontitis have an elevated risk for dysglycemia and insulin resistance [4]. Moreover, some cohort studies have demonstrated that patients with type 2 diabetes and periodontitis have significantly higher hemoglobin A1c (HbA1c) levels compared with patients without periodontitis [4]. people) world-wide [5]. In the Western Pacific area including Japan of the world, the number of people with diabetes is predicted to increase by $31 \%$ between 2019 and 2045 [5]. Furthermore, one in two adults with diabetes are undiagnosed globally (232 million) [5]. Although there are several established and accurate screening tools for DM (A1c, fasting glucose, oral glucose tolerance test), it is important to develop an additional diagnostic method to capture at-risk patients in non-traditional clinical setting for detecting type 2 diabetes in the early stages. 
a screening procedure and reduce medical costs.

$(\mathrm{ABL})$ as a clinical index, together with the high-sensitivity C-reactive protein (hs-CRP) value, which is an

Methods

Design and subjects

The design was a cross-sectional study. Participants were 322 subjects who had a medical checkup in the medical 
body height, body weight, and current smoking history were obtained from the medical records of each subject.

Before the start of this study, written informed consent was obtained from all subjects for their participation in the

(2) Those who have uncontrolled severe cardiac disease, renal dysfunction, or hepatic dysfunction. (3) Those who are taking antibody drugs or anti-inflammatory drugs for autoimmune diseases. (4) Those who have taken any using DIGORA ${ }^{\circledR}$ Optime (Soredex Orion Corp., Tuusula, Finland). 

excluded. in serum.

112 Classification of periodontal disease by severity

114 classification is based on the following categories: ABL of less than $25 \%$ is clinically mild (I), $25 \%$ or more and

115 less than $35 \%$ is moderate (II), $35 \%$ or more is severe (III). On the other hand, a hs-CRP value of less than 440

$116 \mathrm{ng} / \mathrm{ml}$ is mild inflammation (A), $440 \mathrm{ng} / \mathrm{ml}$ or more and less than $1020 \mathrm{ng} / \mathrm{ml}$ is moderate (B), and $1020 \mathrm{ng} / \mathrm{ml}$ or

117 more is severe (C). Combining ABL with hs-CRP yields nine classifications of periodontal disease severity [9] 


\section{8 (Figure 1).}

in age, sex (binary), body mass index (BMI), current smoking history, number of teeth, ABL (three groups), and accurate $(0.9<$ AUROC $<1)$, and perfect tests $($ AUROC $=1)$. All comparisons were two-sided and performed at Japan, Tokyo, Japan). 
BMI $(\mathrm{p}=0.001)$, number of teeth $(\mathrm{p}<0.001)$, ABL $(\mathrm{p}<0.001)$, hs-CRP $(\mathrm{p}<0.001)$, and periodontal disease

IIIC. The distribution of type 2 diabetes was the highest in group IIIC with $60.0 \%$, followed by group IIIB with

interval $[\mathrm{CI}]=1.042-1.1124, \mathrm{p}<0.001)$ and $\mathrm{BMI}(\mathrm{OR}=1.175,95 \% \mathrm{CI}=1.061-1.301, \mathrm{p}=0.002)$. Additionally, group IIIC $(\mathrm{OR}=12.386,95 \% \mathrm{CI}=2.464-62.276, \mathrm{p}=0.002)$ when compared with group IA (Table 2$)$.

Discussion 
in patients with periodontal disease was approximately twice as high as in patients without periodontal disease

$161[18,19]$. In a cohort study in Hisayama town, it was reported that the prevalence of periodontal disease was

there is little detailed data on the relationship between the two diseases in Japan. One reason for this gap in the literature is that there has been no unified standard for evaluating periodontal disease.

174 ABL; however, it does not reflect the situation when a periodontal pocket has healed. The hs-CRP value, which is a biomarker for inflammation, was defined according to the Hisayama study [24] and consists of three stages: 
177 periodontal disease; however, it is a highly sensitive marker suited to measuring periodontal disease, which is

178 regarded as a mild chronic inflammation. Previous studies have reported that hs-CRP levels are often high in

179 patients with severe periodontitis and decrease with treatment $[23,25]$. This study is also an important

180 epidemiological study to evaluate whether these classifications are valid.

The main result of this study was that the rate of ABL had a higher AUROC value than hs-CRP,

suggesting that individuals who have type 2 diabetes may be identified from the results of ROC analysis.

Furthermore, in logistic regression analysis, the IIIA, IIIB, and IIIC groups with an alveolar bone resorption rate

of $35 \%$ or more were associated with type 2 diabetes, regardless of the hs-CRP value. These findings indicate that 
periodontal disease and identify at-risk patients for type 2 diabetes.

and thus lived in a specific region of Japan; they were not representative of the entire population. Second, we did number of classifications of periodontal disease severity into nine groups should be improved for better analysis.

211 ABL, which can be identified by oral radiographs taken at the time of dental treatment, and hs-CRP may be 
215 The authors thank the study participants and the staff of Matsumoto Dental University Hospital.

216

217 Author's contributions

218 Study design: N.Y., A.T.; Data collection: Y.I., N.Y.; Formal analysis and writing: A.T., N.Y., Y.I., N.D.; Data-

219 interpretation: A.T., N.Y., N.D.; Critical review: N.U. All authors have read and agreed to the publication of the

220 final version of the manuscript.

221

$222 \quad$ Funding

223 This study was supported by the Japan Society for the Promotion of Science, Grants-in-Aid for Scientific Research

224 (18K09758).

225 Availability of data and materials

226 The datasets used and/or analysed during the current study are available from the corresponding author on

227 reasonable request.

228

229 Declarations

230 Consent for publication

231 Not applicable.

232

233 Competing interest 
The authors declare that they have no competing interests.

Ethics approval and consent to participate

All subjects were informed of the results of this study in accordance with the ethics guidelines of the Ministry of

Health, Labour and Welfare and the Ministry of Education, Culture, Sports, Science and Technology. The

Institutional Review Board for Clinical Research at Matsumoto Dental University reviewed and approved this

\section{References}

244 1. Kidambi S, Patel SB. Diabetes mellitus: considerations for dentistry. J Am Dent Assoc. 2008;139 Suppl:8s-18s.

2. Jepsen S, Blanco J, Buchalla W, Carvalho JC, Dietrich T, Dörfer C, et al. Prevention and control of dental caries and periodontal diseases at individual and population level: consensus report of group 3 of joint EFP/ORCA workshop on the boundaries between caries and periodontal diseases. J Clin Periodontol. 2017;44 Suppl 18:S85-s93.

3. Meyle J, Chapple I. Molecular aspects of the pathogenesis of periodontitis. Periodontol 2000. 2015;69(1):7-17.

4. Sanz M, Ceriello A, Buysschaert M, Chapple I, Demmer RT, Graziani F, et al. Scientific evidence on the links between periodontal diseases and diabetes: Consensus report and guidelines of the joint workshop on periodontal diseases and diabetes by the International Diabetes Federation and the European Federation of Periodontology. J Clin Periodontol. 2018;45(2):138-49.

5. . IDF DIABETES ATLAS Ninth edition 2019. 2019.

6. Eke PI, Page RC, Wei L, Thornton-Evans G, Genco RJ. Update of the case definitions for population-based surveillance of periodontitis. J Periodontol. 2012;83(12):1449-54.

7. Tonetti MS, Greenwell H, Kornman KS. Staging and grading of periodontitis: Framework and proposal of a new classification and case definition. J Periodontol. 2018;89 Suppl 
8. Leroy R, Eaton KA, Savage A. Methodological issues in epidemiological studies of periodontitis--how can it be improved? BMC Oral Health. 2010;10:8.

9. Nishimura F, Yamazaki K, Nomura Y, et al. Final report of Working Group on classification by severity of periodontal disease. The Periodontal Medicine Committee, the Japanese Society of Periodontology. J Japan Society of Periodontology 2011;53(3):197-200.

10. Kim TS, Obst C, Zehaczek S, Geenen C. Detection of bone loss with different X-ray techniques in periodontal patients. J Periodontol. 2008;79(7):1141-9. Bassiouny MA, Grant AA. The accuracy of the Schei ruler: a laboratory investigation. J

15. Saito T, Shimazaki Y, Kiyohara Y, Kato I, Kubo M, Iida M, et al. The severity of periodontal

16. Saremi A, Nelson RG, Tulloch-Reid M, Hanson RL, Sievers ML, Taylor GW, et al.

17. Shultis WA, Weil EJ, Looker HC, Curtis JM, Shlossman M, Genco RJ, et al. Effect of

18. Soskolne WA, Klinger A. The relationship between periodontal diseases and diabetes: an overview. Ann Periodontol. 2001;6(1):91-8.

20. Taylor GW, Burt BA, Becker MP, Genco RJ, Shlossman M, Knowler WC, et al. Severe

21. Friedewald VE, Kornman KS, Beck JD, Genco R, Goldfine A, Libby P, et al. The American

19. Demmer RT, Jacobs DR, Jr., Desvarieux M. Periodontal disease and incident type 2 diabetes: results from the First National Health and Nutrition Examination Survey and its epidemiologic follow-up study. Diabetes Care. 2008;31(7):1373-9. periodontitis and risk for poor glycemic control in patients with non-insulin-dependent diabetes mellitus. J Periodontol. 1996;67(10 Suppl):1085-93.

Journal of Cardiology and Journal of Periodontology Editors' Consensus: periodontitis and atherosclerotic cardiovascular disease. Am J Cardiol. 2009;104(1):59-68.

22. Nakarai H, Yamashita A, Takagi M, Adachi M, Sugiyama M, Noda H, et al. Periodontal 
300

301

302

303

304

305

306

307

308

309

310

311

312

313

314

\section{$315 \quad$ Figure legends}

316 Figure 1. Number of subjects according to classification of periodontal disease severity

317 ( ): number of patients with type 2 diabetes

318

319

320

321

322

323

disease and hypertriglyceridemia in Japanese subjects: potential association with enhanced lipolysis. Metabolism. 2011;60(6):823-9.

23. Nakajima T, Honda T, Domon H, Okui T, Kajita K, Ito H, et al. Periodontitis-associated upregulation of systemic inflammatory mediator level may increase the risk of coronary heart disease. J Periodontal Res. 2010;45(1):116-22.

24. Arima H, Kubo M, Yonemoto K, Doi Y, Ninomiya T, Tanizaki Y, et al. High-sensitivity Creactive protein and coronary heart disease in a general population of Japanese: the Hisayama study. Arterioscler Thromb Vasc Biol. 2008;28(7):1385-91.

25. Nishimura F, Taniguchi A, Iwamoto Y, Soga Y, Fukushima M, Nagasaka S, et al. Porphyromonas gingivalis infection is associated with elevated $\mathrm{C}$-reactive protein in nonobese Japanese type 2 diabetic subjects. Diabetes Care. 2002;25(10):1888.

26. Dewake N, Ishioka Y, Uchida K, Taguchi A, Higashi Y, Yoshida A, et al. Association between Carotid Artery Calcification and Periodontal Disease Progression in Japanese Men and Women: A Cross-Sectional Study. J Clin Med. 2020;9(10).

Figure 2. ROC curve of effective factors for screening for type 2 diabetes. The green line represents alveolar bone loss; the blue line represents high-sensitivity $\mathrm{C}$-reactive protein value. 
Figures

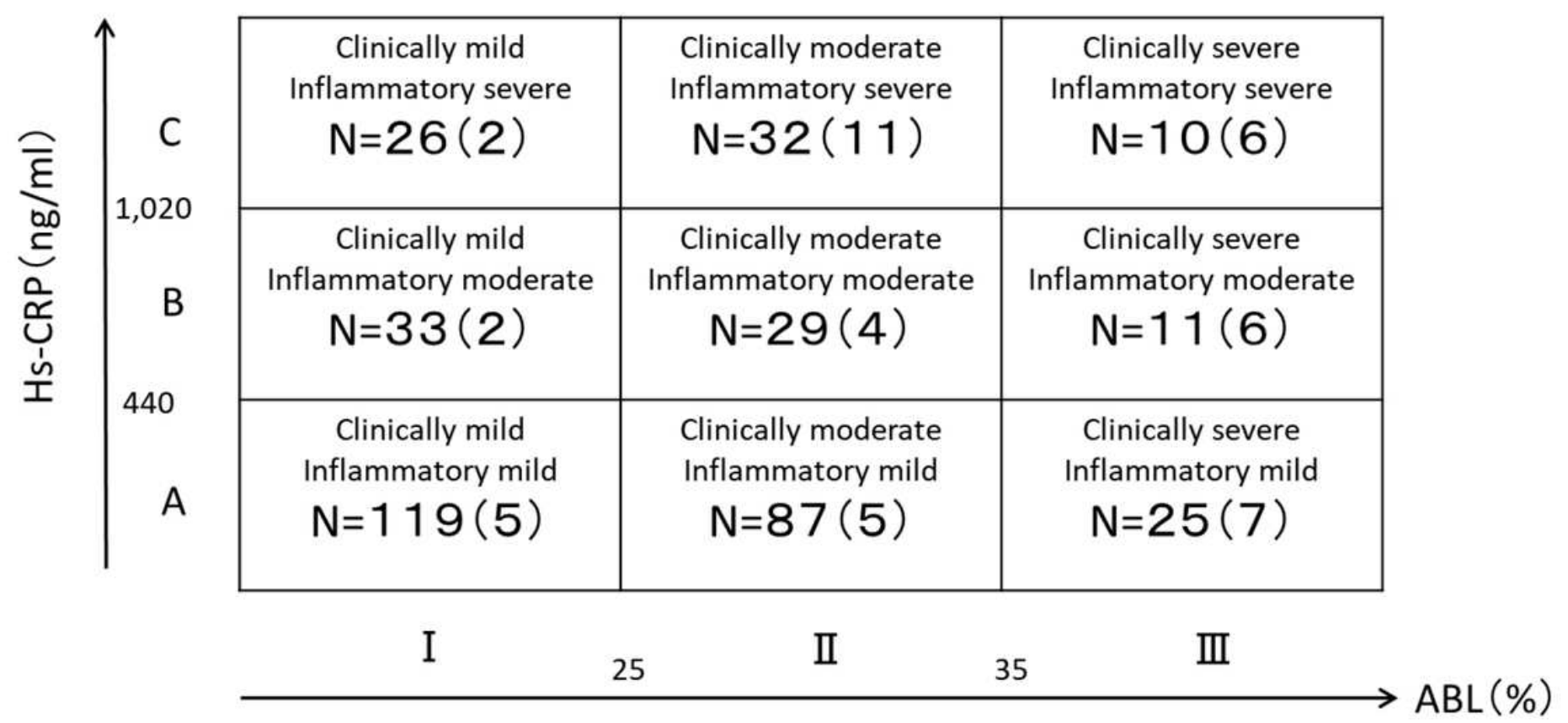

\section{Figure 1}

Number of subjects according to classification of periodontal disease severity ( ): number of patients with type 2 diabetes 


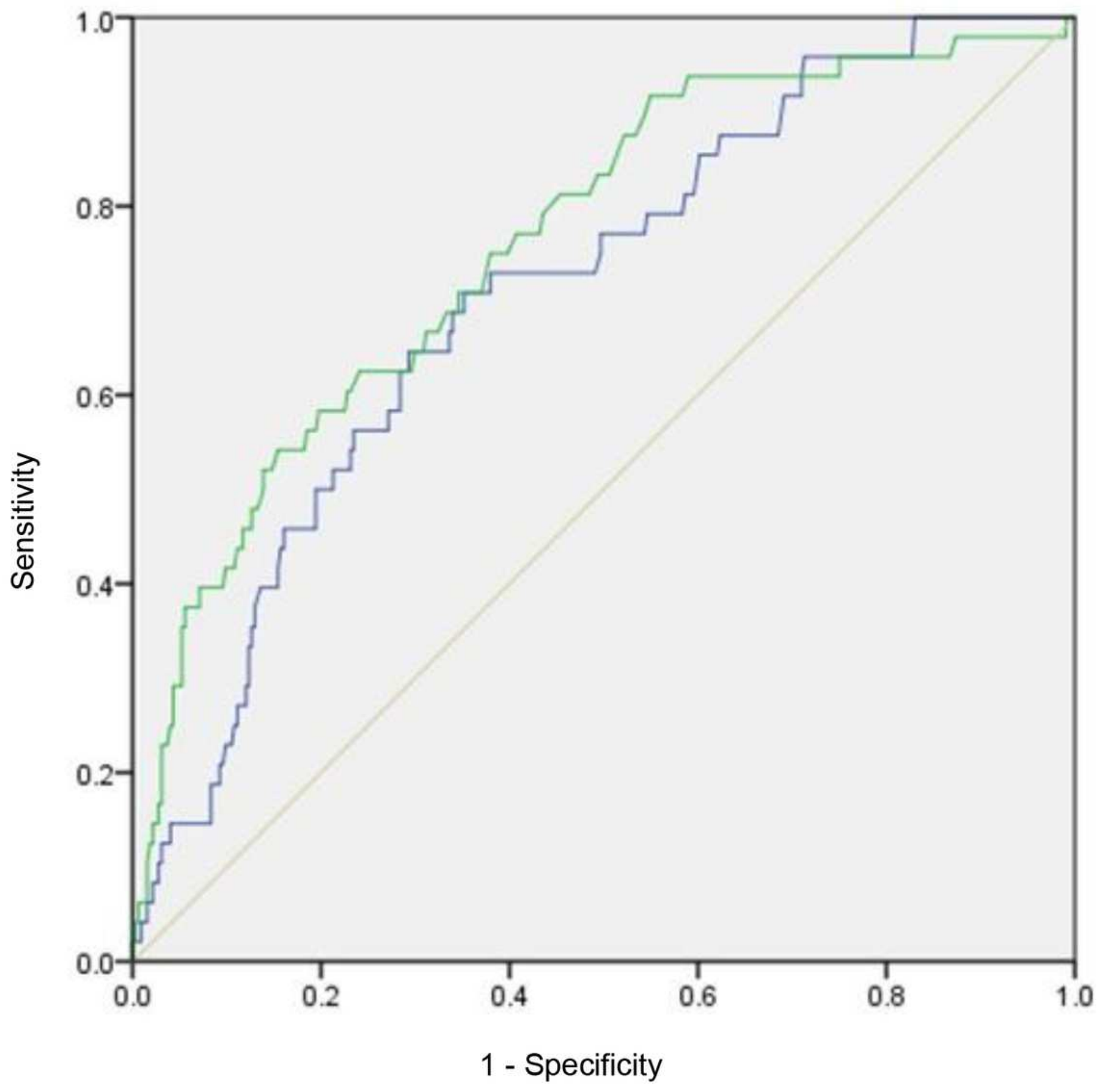

Figure 2

ROC curve of effective factors for screening for type 2 diabetes. The green line represents alveolar bone loss; the blue line represents high-sensitivity $\mathrm{C}$-reactive protein value.

\section{Supplementary Files}

This is a list of supplementary files associated with this preprint. Click to download. 
- Tab.dewake.pdf 